\title{
Spastic paraplegia type 7
}

INSERM

\section{Source}

INSERM. (1999). Orphanet: an online rare disease and orphan drug data base. Spastic paraplegia type 7. ORPHA:99013

Autosomal recessive spastic paraplegia type 7 is a form of hereditary spastic paraplegia (see this term) characterized by an onset usually in adulthood (but rang ing from 10-72 years) of progressive bilateral lower limb weakness and spasticity, sphincter dysfunction, decreased vibratory sense at the ankles and with additional manifestations including optical neuropathy, nystagmus, strabismus, decreased hearing, scoliosis, pes cavus, motor and sensory neuropathy, amyotrophy, blepharoptosis and ophthalmoplegia. 